\title{
La ciudad prospectiva
}

\author{
Fernando Ángel MoReno e Ivana PALIBRK \\ Departamento de Lengua Española, Teoría de la Literatura y \\ Literatura Comparada \\ Universidad Complutense de Madrid \\ famoreno@filol.ucm.es
}

\section{Resumen}

En este análisis se explican el origen y las características de la ficción prospectiva respecto a los restantes géneros proyectivos. A continuación, se caracteriza la ciudad prospectiva y se desarrollan las posibilidades que ofrece. Finalmente se plantean diferentes tipos de ciudades prospectivas desarrollados en literatura, cine y cómic, con ejemplos concretos.

Palabras clave: ciudad, prospectiva, ciencia ficción, cómic, Blade runner, ciberpunk.

Title: The Prospective City

\section{Abstract}

This analysis explains the origin and the main features of the prospective fiction, with regard to other projective genres. In addition, the prospective city, as well as its interpretive possibilities, are being portrayed and developed. Finally, the article analyses some different types of prospective cities displayed in literature, films and comic books, through precise examples.

Keywords: city, prospective, science fiction, comics, Blade runner, cyberpunk.

\section{Índice}

1. Los géneros proyectivos

2. La ciudad prospectiva

3. Algunas posibilidades de la ciudad prospectiva

3.1. Edificios metonímicos y simbólicos

3.2. Ciudades cubiertas

3.3. Ciudades simuladas

3.4. Ciudades siniestras

3.5. Ciudades abandonadas

3.6. La ciudad invadida

3.7. Space opera

4. Conclusiones

\section{Los géneros proyectivos}

Resulta muy probable que numerosos investigadores desconozcan a qué se refiere el término "ficción prospectiva" o incluso que duden a la hora de clasificar ciertas obras dentro de la ciencia ficción. Esta situación se debe al escaso interés que ha existido en nuestro país por los estudios de ciencia ficción. Estos estudios han sido 
desarrollados casi siempre por periodistas, escritores o incluso meros aficionados, por lo que carecemos prácticamente de bibliografía científica dentro del mundo académico. Por fortuna, el aumento del número de tesis doctorales defendidas que se centran en obras del género, algunos artículos rigurosos, algunos congresos y seminarios, y los sucesivos premios con los que se la está vinculando, están introduciendo desde hace unos siete ocho años un ligero cambio en los estudios sobre un conjunto de obras desarrollado a lo largo de más de cien años de historia. En este sentido, la oportunidad que brinda Ángulo Recto resulta encomiable al proponer el acercamiento a uno de los elementos más importantes de este tipo de literatura: la ciudad. Antes de clarificar las estrechas vinculaciones entre la ciudad y la ficción prospectiva, verdadero objetivo de esta introducción al dossier, nos permitiremos aclarar los términos para aquellos que precisen de algunos matices iluminadores.

La ciencia ficción es uno de los tres grandes géneros proyectivos, que en sí mismos abarcan infinidad de subgéneros narrativos. Estos géneros son la literatura maravillosa, la literatura fantástica y la literatura de ciencia ficción (Moreno 2010: 80-123). Los tres parten de que el lector modelo de cada obra concreta asume de una manera cotidiana una percepción de la realidad puramente materialista, en las líneas establecidas por el materialismo filosófico y la mayor parte de las corrientes positivistas y existencialistas desarrolladas desde finales del siglo XIX. Es decir, se parte de la consideración de que no existen los fantasmas, de que existe una realidad definible y más o menos cuantificable 0 , al menos, vivimos habitualmente con esa impresión de que existe ${ }^{1}$.

De este modo, un fantasma, viajar en el tiempo, superar la velocidad de la luz, un vampiro o un conjuro mágico son tomados por la mayoría de los ciudadanos occidentales como imposibilidades físicas en nuestra sociedad actual. Los géneros proyectivos introducen en sus argumentos motivos relacionados con estas posibilidades.

La diferencia entre los géneros queda establecida por las cláusulas ficcionales que el texto propone y que el lector acepta a través del pacto de ficción. En este sentido, cada género propone un contrato de ficción diferente con el que el lector puede establecer el correspondiente pacto durante la lectura.

El contrato ficcional maravilloso acepta que en el argumento de la obra aparezcan sucesos sobrenaturales sin que dichos sucesos

\footnotetext{
1 Para las relaciones entre nuestros conceptos actuales de "realidad" y el género fantástico, recomendamos consultar los trabajos de David Roas (2008 y 2011). Pese a discrepar en la consideración sobre la realidad que se presenta en dichos trabajos, nos parece imprescindible el acercamiento a la discusión que el teórico de la literatura propone.
} 
resulten traumáticos por su naturaleza ontológica para los personajes e incluso para el lector. Subgéneros clásicos de esta literatura maravillosa son el realismo mágico, con textos como Cien años de soledad, o la fantasía heroica, casi siempre representada por El señor de los anillos. La experiencia catártica de los hechizos del mago Gandalf, por ejemplo, se encuentra íntimamente relacionada con el asombro y la maravilla.

El contrato ficcional fantástico también acepta fenómenos sobrenaturales, pero la repentina aparición de dichos fenómenos resulta inconcebible ontológicamente para alguno de los personajes $y$, por lo general, para el lector, quienes sufren un trauma epistemológico acerca de la realidad. Julio Cortázar escribió numerosos relatos fantásticos y podríamos incluir también aquí ciertos relatos de Poe, Hoffmann, Maupassant y Stephen King, así como algunos de Borges. La experiencia catártica del hundimiento de la casa Usher se encuentra íntimamente relacionada con el desasosiego y la inquietud ante una realidad que de repente se vuelve inaprehensible.

El contrato ficcional de la ciencia ficción no acepta fenómenos sobrenaturales, por muy peregrina o difusa que sea la justificación científica o racional de los elementos no cotidianos que se planteen. Se trata quizás del género narrativo con mayor cantidad de subgéneros: utopías, distopías, ucronías, viajes en el tiempo, ciberpunk, steam-punk, robots, BEM, ficciones postapocalípticas, relatos del primer contacto, naves generacionales, space opera, hard... Tal heterogeneidad de subgéneros ha provocado una tradición de ambigüedades definitorias y clasificadoras (Moreno 2010: 105108). Célebres obras de ciencia ficción son Nosotros, Crónicas marcianas, 2001, una odisea espacial, 1984, Un mundo feliz... La experiencia catártica del encuentro con una sociedad en la que no existe la religión o del diálogo con una máquina cuyo intelecto supera al humano se encuentra generalmente relacionada con la reflexión intelectual y con el desasosiego respecto a apriorismos culturales, aunque también se centra en múltiples ocasiones en lo asombroso, desde una perspectiva diferente a la del contrato ficcional maravilloso. 


\section{La ciudad prospectiva}

La ficción prospectiva es la rama de la ciencia ficción que emplea las herramientas del género para desarrollar crítica cultural, política, social, filosófica, económica... El término fue acuñado por Julián Díez (2008) y reutilizado como concepto clave con matices diferentes (Moreno 2010). Díez lo emplea para clasificar un conjunto de obras que comparten una serie de rasgos dominantes específicos desde el siglo XIX y que, tras cierta evolución durante el siglo XX, terminaron siendo vinculadas por el público con la ciencia ficción. Es el caso de la novela El amor dentro de 200 años, que Mariano Martín Rodríguez estudia para este dossier monográfico. Toda la tradición utópica y distópica de la modernidad entraría aquí: Nosotros, 1984, Un mundo feliz... Por otro lado, se puede contemplar como una tendencia de la crítica cultural que desarrollan en mayor o menor medida ciertas obras de la ciencia ficción.

Pese a las divergencias entre estas propuestas, ambas contemplan lo prospectivo como una herramienta de crítica cultural, vinculada en cierta medida con el género de la ciencia ficción. La potencialidad estética de este género es ilimitada, como han demostrado numerosos escritores de la talla de J. G. Ballard, Stanislaw Lem, Ursula K. Le Guin, Margaret Atwood, Philip K. Dick o Ray Bradbury. Por fortuna, el mundo anglosajón aporta numerosos trabajos como los de Suvin (1984), Csicsery-Ronay (2008) o Jameson (2005), e incluso disponemos de obras esenciales en español (Ferreras 1972) y en otras lenguas, como los estudios de Cornel Robu $(2006)^{2}$.

Podemos entrar ahora en el tema concreto del presente dossier. Si se acepta la terminología que proponemos, la conclusión inmediata consistiría en defender que dicho dossier debería centrarse únicamente en obras prospectivas. Sin embargo, paradójicamente, no ha sido así. Los lectores encontrarán unas páginas más adelante estudios sobre obras que no cabe aceptar como absolutamente prospectivas, aunque desde luego todas ellas puedan adscribirse al género de la ciencia ficción. El motivo es teórico y práctico al mismo tiempo, pues viene motivado por cualquier análisis que se realice $y$, al mismo tiempo, responde a cuestiones esenciales relacionadas con el propio concepto "ciudad".

Podemos postular que cualquier aparición de una ciudad dentro de una obra de ciencia ficción representa, por su mera presencia, una orientación prospectiva, en cuanto a que responde a una

${ }^{2}$ En cuanto a revistas especializadas en estudios sobre ciencia ficción o en géneros proyectivos en general, deben citarse Science Fiction Studies, Foundation y Extrapolation, entre las anglosajonas, y Hélice: Reflexiones críticas sobre ficción especulativa, si nos acercamos a la lengua castellana. 
consideración previa respecto a lo que dicha ciudad implica en la lectura del elemento proyectivo no sobrenatural. Es decir, aunque desarrollemos una trama de space opera basada solo en batallas espaciales y aventuras galácticas, cada ciudad que aparezca en dicha trama tendrá que ver con una proyección de nuestras ciudades reales en una realidad social enormemente distinta de la nuestra $y$, por consiguiente, con implicaciones culturales significativas. El mejor ejemplo lo encontramos en la saga de aventuras espaciales Star Wars, creada y desarrollada cinematográficamente por George Lucas. En esta saga encontramos el planeta Coruscant, que es en sí mismo una colosal ciudad sin espacio para el ámbito rural. Una ciudad que no se contrapone al campo y a la naturaleza más que a través de la ausencia de los mismos ya implica consideraciones prospectivas.

Por este motivo, proponemos el concepto de "ciudad prospectiva" para aquellos entornos urbanos que se ven afectados por el contrato ficcional de la ciencia ficción, sea el resto de la obra prospectiva o no. Del mismo modo, por este motivo, invitamos a estudiar desde esta perspectiva cualquier ciudad que aparezca en una obra de ciencia ficción ${ }^{3}$.

Sin embargo, en numerosas ocasiones, el término "ciudad" puede ser complicado en cuanto a su aplicación a ciertos entornos sociales (humanos o extraterrestres), dada la enorme variedad estética de propuestas que el género permite. ¿Consideramos una nave generacional como ciudad? Se trata de una nave espacial que viaja durante cientos de años y que se encuentra habitada por sucesivas generaciones humanas. ¿Consideramos "ciudad" los rascacielos de la novela de J. G. Ballard del mismo nombre, con sus restaurantes, piscinas, escuelas, capillas, diferencias sociales y económicas...? ¿Qué concepto de ciudad vive el habitante de la Tierra en Mundo anillo, de Larry Niven, que mediante teletransportadores disponibles en las aceras puede desayunar en París, trabajar en Tokyo, almorzar en Melbourne, cenar en Marrakech y hacer el amor en Vancouver?

Desde Frankenstein, considerada tradicionalmente la primera novela de ciencia ficción, disponemos de casi doscientos años de propuestas estéticas. Se trata de todo un universo integrado por sorprendentes y cautivadores entornos urbanos, asentamientos sociales, extrañas concepciones de la ciudad. Tantos ejemplos resultan absolutamente imposibles de recopilar y clasificar, y mucho menos desde las propuestas científicas actuales, por muy interesantes y rigurosas que estas sean, y a pesar de lo mucho que pueden aportar al estudio de estas ciudades prospectivas.

3 Ya encontramos algunos acercamientos que responden a esta perspectiva, como los estudios sobre utopías y distopías desarrollados por Fredric Jameson (2005). 
Por el momento, nos limitaremos a señalar algunas posibilidades de estudio relacionadas con diferentes tipos de acercamiento al concepto de ciudad prospectiva.

\section{Algunas posibilidades de la ciudad prospectiva}

Resultaría absurdo intentar un minucioso estudio sobre la ciudad prospectiva en su conjunto, así que limitaremos esta introducción a señalar diferentes posibilidades que el motivo ofrece, como una invitación a futuros investigadores y como una presentación a los trabajos del presente dossier. Podemos acercarnos a las ciudades prospectivas desde muy diferentes parámetros, que van desde sus elementos arquitectónicos hasta su concepto, pasando por su estructura urbana o su localización geográfica, sin descartar las especies que las habitan. Cada posibilidad se combina con otras, sin que sea posible traducirlas independientemente en términos de significado absoluto. Así, semióticamente definen parte del concepto estético de la obra y, de manera simultánea, se definen a partir del mismo. Por consiguiente, las posibilidades que propondremos de manera muy superficial a continuación no pretenden relacionar de manera estricta y unívoca el concepto presentado con la ciudad de cada ejemplo, sino que dichos ejemplos resultan susceptibles de ser estudiados desde la óptica propuesta, aunque no exclusivamente desde esta.

\subsection{Edificios metonímicos y simbólicos}

Todos los elementos arquitectónicos de las ciudades prospectivas remiten de manera obvia a las ideologías implícitas en la trama, bien ideológicamente, bien desde la intuición emocional. Los ejemplos más claros se ven en el cine, lenguaje especialmente idóneo, como el cómic, para desarrollar el concepto. Por lo general, se trata de la mejor representación de los principios distópicos, como observamos a través del extenso, complejo y profundo estudio de David Conte sobre las ciudades oscuras de François Schuiten que presentamos en este dossier.

En este sentido, podríamos casi hablar de una ciudad prospectiva limpia y una ciudad prospectiva sucia, según se pretenda manifestar la frialdad y la obsesión por el control de las personas o la degradación y decadencia de la cultura humana, representadas a través del entorno urbano. Ciudad prospectiva limpia es, claramente, Gattaca, donde la obsesión por el control genético para eliminar las imperfecciones de la Humanidad es la parte esencial de la trama. En esta película, el protagonista miente a todos al pretender ser un humano perfecto genéticamente, por lo que todos los días debe rasurarse y limpiarse absolutamente para eliminar cualquier posibilidad de rastro orgánico. La película comienza con un análisis minucioso de esta limpieza, que puede rastrearse en la simetría, los 
colores fríos y las construcciones impersonales. La extrema limpieza de todos los espacios urbanos.

La base de estas ciudades, como la de todas las novelas distópicas, es la extraordinaria novela de Evgueni Zamiatin Nosotros, que influiría enormemente en A Brave New World, de Aldous Huxley, y en 1984, de George Orwell.

En cuanto a la ciudad prospectiva sucia, el mejor ejemplo es sin duda Blade Runner, de Ridley Scott, con su horror vacui y sus edificios simbólicos. No en vano, la decadencia urbana de Blade Runner inició el género del cyberpunk a través de la novela Neuromancer, de William Gibson. Los lectores interesados encontrarán en este dossier un buen análisis de esta película y de otras adaptaciones de la obra de Dick dentro del trabajo de Javier Rivero Grandoso.

En el ciberpunk se aprecia un fuerte contraste entre la limpieza interior del zigurat, dominado por grandes corporaciones que gobiernan a los estados (hecho que se ha convertido en horrible realidad), y la suciedad de las calles donde viven los ciudadanos. Por otra parte, el zigurat aparece como metonimia del dios creador que lo habita ${ }^{4}$.

Representa un lujo disponer para este dossier de un trabajo de un experto en literatura fantástica, como es Daniel Ferreras (1995), sobre los espacios urbanos distópicos. Ya al principio de su propuesta reflexiona sobre las interesantes posibilidades del paradigma urbano en su aplicación a los géneros proyectivos. A continuación se atreve a enfrentarse con una de las obras más complejas y paradigmáticas de la ficción prospectiva: este Neuromancer, de William Gibson, que tratábamos. El estadounidense construyó una de las más inquietantes y reveladoras ciudades prospectivas, lúcidamente analizada por Ferreras.

El ejemplo de edificio simbólico más conocido de la literatura prospectiva es el cobertizo donde vive el niño del cuento "Los que se alejan de Omelas", de Ursula K. Le Guin. Omelas es la ciudad ideal, el paraíso utópico sobre la tierra, donde todo es perfecto y saludable. El único problema es que periódicamente, a cambio de esta felicidad, todo habitante de Omelas debe maltratar a un niño que vive en condiciones deplorables en un cobertizo. Muchos abandonan la ciudad de Omelas.

\footnotetext{
4 Ya impresiona por sí misma la bibliografía que toca de un modo u otro la arquitectura en Blade Runner. Algunos ejemplos de estudios sobre Blade Runner, 0 sobre arquitectura y cine prospectivo son los de Barber (2006), Benjamin (1994), Milner (2004), Neumann (1996), Adiyan (1993), Montaner (1991 y 2001), Sambricio (1996). Para una extensa bibliografía sobre arquitectura en el cine, vid.: http://www.lib.berkeley.edu/MRC/cinematiccity.html
} 


\subsection{Ciudades cubiertas}

La ciudad como expresión rousseauniana de defensa contra la naturaleza, contra un entorno hostil, se encuentra representada en toda la narrativa prospectiva a través de la imagen de la ciudad cubierta. Me refiero a todas esas ciudades protegidas no ya por murallas, sino completamente cubiertas por cúpulas o por piedra o cemento. Los ejemplos son numerosos. Quizás las más fáciles de localizar sean las ciudades submarinas del planeta Naboo, en Star Wars: The Phantom Menace, de George Lucas, donde habitan los gungas. Resulta interesante la relación simbiótica que el propio discurso de la película defiende que existe con las ciudades abiertas de la superficie del mismo planeta. Otras ciudades cubiertas por cúpulas son la de Naufragio en tiempo real, de Vernon Vinge, donde la cúpula protege incluso del paso del tiempo, puesto que la comunidad descrita viaja en conjunto a través de los milenios. En el cómic es célebre la ciudad de los Inhumanos, seres tan evolucionados mental y físicamente respecto a los humanos que deben exiliarse a una ciudad lunar protegida por una cúpula. Esta idea de una cúpula que protege del ambiente hostil del vacío no es tanto una ficción como el único medio mediante el que podría comenzarse una colonización del cosmos. No en vano, abundan los ejemplos, como el de la película Total Recall, de Paul Verhoeven. En estos casos, resulta especialmente característico el contraste entre el bullicioso ruido de la ciudad bajo la cúpula y el silencio espectral del exterior.

Sin embargo, quizás sean más interesantes las de la novela de Robert Silverberg El mundo interior, donde no existen ciudades en la superficie y donde la claustrofobia de las ciudades subterráneas se relaciona con las extrañas costumbres sociales de los ciudadanos. En cómic abundan especialmente los ejemplos de ciudades desarrolladas en las cloacas, como una macabra y decadente representación de las ciudades convencionales, como las de los morlocks en los cómics Marvel. A menudo sus habitantes son mutantes, humanos deformes, como extensión de la perversión urbana que habitan.

\subsection{Ciudades simuladas}

El género demiúrgico es un género cinematográfico que se basa en el contraste entre una realidad que sus habitantes consideran verdadera y la realidad auténtica que deben descubrir. Es frecuente en este cine que la ciudad simulada sea una representación, de algún modo ideal, de las ciudades convencionales. El mejor ejemplo es la ciudad de The Truman Show, de Peter Weir, que es también una ciudad cubierta por una cúpula. En ella se nos muestra el ideal estadounidense de la comunidad adinerada a través de un programa de televisión en el que vive el protagonista sin saberlo.

Es muy interesante en este sentido la ciudad simulada de la película The Matrix, de los hermanos Wachowski, que parece 
exactamente igual que la nuestra. El creador de esta realidad simulada, el arquitecto, llega a explicar que en un principio se les proporcionó a los seres humanos una ciudad simulada ideal, donde fueran felices, pero sus habitantes rechazaron esa perfección.

Otra interesante idea de estas ciudades simuladas la encontramos en el principio por el cual los límites de la ciudad significan el límite del universo, puesto que la simulación termina donde empieza lo rural. Las carreteras, de repente, se cortan cuando el protagonista intenta escapar de la ciudad simulada con su coche, como en The Thirteen Floor, de Josef Rusnak, o en Dark City, de Álex Proyas. En este sentido, no existe vida ni interés ni ser más allá del espacio urbano.

Si alguien dudara de la fuerza simbólica e ideológica de la ciudad prospectiva cerrada, dispone del estudio de Antonio Sánchez Domínguez que presentamos en este dossier. En él conocemos cómo Speer, el célebre arquitecto de Hitler, conjugó ideas filosóficas y totalitarias para imaginar un futuro que conjugaba ideología, ciudades, futuro y literatura.

\subsection{Ciudades siniestras}

Parece bastante chocante que todos los arquitectos de una ciudad se hayan puesto de acuerdo para crear sus edificios a partir de estructuras aterradoras, colores oscuros y esculturas demoníacas. Sin embargo, encontramos este tipo de ciudades con relativa frecuencia en el cine y en el cómic prospectivos. El ejemplo más característico es la Gotham City de las películas y los cómics de Batman, empleada como antítesis de la limpia y luminosa Metrópolis de Superman. Llama la atención cómo en Gotham casi siempre es de noche (lo mismo sus historias se desarrollan en solo seis meses de vida en Alaska y nadie nos lo había dicho) y en Metrópolis casi siempre es de día. De este modo representan diferentes imágenes colectivas de lo que es una ciudad.

La ciudad de la ya citada película Dark City representa otro magnífico ejemplo de ciudad siniestra, en cuanto que se trata de una ciudad simulada por unos extraterrestres poco menos que demoníacos.

Todas las ciudades siniestras del siglo $\mathrm{XX}$ tienen su origen en una ciudad abandonada: la terrorífica ciudad antártica de En las montañas de la locura, de Howard Philips Lovecraft, que representa a la perfección la idea de su autor de que cualquier sociedad e inteligencia no humana resultaría demoníaca, terrorífica y enloquecedora para nosotros. En la novela de Lovecraft, la ciudad es un personaje, y la descripción de sus distintos edificios representa una malsana metonimia de las ciudades convencionales. 


\subsection{Ciudades abandonadas}

Quizás se trata del tipo de ciudad prospectiva más característica, aparte de la de la space opera, que veremos a continuación. Las ciudades abandonadas representan el terror a la muerte y a la continuidad de un mundo silencioso y entrópico tras nuestra desaparición. Los ejemplos de ciudad abandonada son tan abundantes que casi configura un subgénero en sí misma. Existe toda una línea de ciudades extraterrestres abandonadas que son estudiadas por equipos de xenoarqueólogos o por aventureros, como las fascinantes ciudades de las novelas Las máquinas de Dios, de Jack McDevitt, o Pórtico, de Frederik Pohl. No obstante, lo más frecuente es la exhibición de ciudades conocidas por nosotros que han sufrido un cataclismo de cualquier tipo: nuclear, por epidemias, por un meteorito...

El ejemplo más impresionante quizás sea el de La tierra permanece, magnífica novela de George Stewart donde se insiste en la pérdida de la cultura humana. Impresiona especialmente el capítulo en el que el protagonista entra en las bibliotecas abandonadas para acabar por resignarse ante el hecho de que no podrá salvar la mayor parte de los libros de su degradación y destrucción. También significativa puede ser El mundo sumergido, de James Graham Ballard, con un Reino Unido sumergido bajo las aguas.

El cine se ha regodeado a menudo con esta idea, como en los casos de The Omega Man, de Boris Sagal, y de I Am Legend, de Francis Lawrence, basadas en otra extraordinaria novela escrita por Richard Matheson, también titulada I Am Legend.

Toda ficción postapocalíptica, se desarrolle en el lenguaje estético que se desarrolle, suele expresar la fugacidad de la cultura humana y de sus convenciones sociales, así como la soledad del individuo.

Como interesantísima muestra del motivo, disponemos en este dossier del minucioso trabajo de Annelies Oeyen, que demuestra con su estudio el gran interés de la literatura prospectiva argentina.

\subsection{La ciudad invadida}

Una variable de la ciudad postapocalíptica es la ciudad invadida, que se sitúa en diferente epígrafe debido a que no se encuentra estrictamente abandonada. Se trata de ciudades que han sufrido algún tipo de apocalipsis, pero que han caído en la anarquía.

El ejemplo más claro es el de la ficción con zombis, género cuyas pautas modernas fueron establecidas por George Romero en su clásica Night of the Living Dead, aunque se trataba de una película fantástica, no prospectiva. El zombi simboliza a menudo la manera en que el individuo se siente alienado ante una sociedad que considera ignorante y agresiva. El ejemplo más fascinante, aparte de todos los cinematográficos es, en nuestra opinión, el cómic The Walking Dead, 
de Robert Kirkland. Los supervivientes al holocausto zombi ensayan progresivos sistemas de vida en comunidad e incluso intentan desarrollar nuevos núcleos urbanos, pero el entorno hostil de la masa caníbal y sin cerebro se lo impide. En cine existe todo un género cinematográfico.

Sin embargo, existen otros ejemplos de ciudades invadidas. El más interesante de todos quizás sea el de la novela Dhalgren, de Samuel R. Delany, una de las más importantes ciudades prospectivas sobre las que jamás se haya escrito. Sin motivo aparente, una ciudad de Estados Unidos cae en un estado de absoluta anarquía donde cada persona puede hacer lo que le venga en gana, sin ningún tipo de restricciones. Cientos de personas pasan por ella, bien para conocerla, bien para pasar un tiempo, bien para instalarse. Uno de los capítulos más desasosegantes es el que describe a una familia que permanece en su apartamento como si nada ocurriera, con el marido saliendo todos los días como si fuera a trabajar, en una negación consciente de que las cosas se han venido completamente abajo.

Otra ciudad interesante es la Ora:Cle, de Kevin O'Donell. Una raza extraterrestre ha invadido la Tierra y asesina a cualquier persona que circule por las calles, aunque respeta a quien permanece en su casa. Así, muchísimas personas pasan toda su vida sin abandonar siquiera su apartamento. De este modo, dentro de la ciudad, se niega a la misma y se la limita a un mero telón de fondo que observar desde la ventana.

\subsection{Space opera}

Hemos dejado para el final la space opera por tratarse quizás de la ciudad prospectiva por excelencia.

El space opera es el género más representativo de la ciencia ficción y quizás, paradójicamente, el que menos se parece al resto. Lo configuran los relatos centrados en aventuras desarrolladas en el espacio exterior, a menudo con grandes batallas espaciales. El género ha configurado un típico concepto de ciudad multicultural, con frecuente presencia de extraterrestres, y con numerosos rasgos urbanos muy diferentes entre sí.

Los ejemplos más comunes son extraíbles de la saga de Star Wars, especialmente en lo que se refiere al espacio puerto del episodio cuatro o al Coruscant de la primera trilogía. En sí mismas, estas ciudades constituyen una hiperbolización de muchos rasgos de la ciudad de los últimos cincuenta años, casi siempre con Nueva York como principal punto de referencia, debido a sus grandes rascacielos y su heterogeneidad étnica, aunque cabe identificarlos con casi cualquier gran ciudad actual, como El Cairo, Shangai o Tokyo.

La máxima expresión de esta hiperbolización urbana son las ciudades-planeta, un motivo recurrente en algunas space opera. Se 
trata de planetas en los que ha desaparecido completamente la naturaleza virgen, puesto que toda su superficie ha sido cubierta por construcciones humanas. Tiene cierta relación con el límite del universo propuesto por algunas ciudades simuladas, como hemos visto. Sin embargo, lo que se toma como naturaleza o como medio rural, de manera sumamente poética, es el espacio exterior. El hombre libre, no civilizado, que desprecia los entornos urbanos, es el piloto espacial que vive con escasa compañía viajando entre las estrellas. Además del Coruscant de Star Wars, la ciudad-planeta más conocida es el Trántor de la saga Foundation, de Isaac Asimov, en sí una proyección de la antigua Roma y, como aquella, se hará caer para desautomatizar al espectador respecto a lo que significó la caída del imperio romano, como el propio Asimov reconocía. Precisamente podemos disfrutar en este dossier, al respecto, de un artículo de Emilia García Escalona y Felipe Hernando Sanz.

Para terminar con este breve y muy superficial reconocido por los tipos de ciudades prospectivas, parece adecuado mencionar la ciudad de space opera más hiperbolizada y que mejor refleja las posibilidades del motivo: la ciudad parodiada de la serie Futurama, de Matt Groening. En ella convergen casi todos los tipos de ciudad prospectiva, según cuál sea el tema del capítulo y sirve, como toda parodia, de excelente primera aproximación a lo que significa el motivo de la ciudad prospectiva.

\section{Conclusiones}

Como representación de todo lo expuesto, nos permitimos que las conclusiones a este trabajo las constituyan un excelente conjunto de estudios sobre ciudades prospectivas. Dan cuenta de la importante imbricación de la ciudad prospectiva con nuestro tiempo, tanto a nivel estético como a nivel socio-cultural.

El éxito de la convocatoria ha sido tal que algunos artículos se han quedado pendientes para el próximo número de Ángulo Recto. En este sentido, resulta ilustrador el gran interés por la ciudad y por estos géneros entre los investigadores que han colaborado, así como su lucidez y la agudeza a lo largo de los análisis. Los trabajos aquí presentados no solo ejemplifican y analizan obras concretas, sino que desarrollan conclusiones sobre la enorme potencialidad de la ficción prospectiva y de la ciencia ficción, perfectamente representadas por ese gran motivo que es la ciudad y sus múltiples elementos.

Esperamos que se disfruten tanto como nosotros hemos disfrutado leyéndolos. 


\section{Bibliografía}

ADIYAN, Frederick T. (1993): The Relationship of Architecture and Science Fiction Films. Leicester: De Montfort University.

BARBER, Stephen (2006): Ciudades proyectadas: cine y espacio urbano. Barcelona: Gustavo Gili.

BENJAMIN, A. E. (1994): "At home with replicants: the architecture of Blade runner". Architectural Design, vol. 64 (November / December), pp. 22-25.

CAMPRA, Rosalba (2008): Territorios de la ficción: Lo fantástico. Sevilla: Renacimiento.

CSICSERY RONAY JR., Istvan (2008): The Seven Beauties of Science Fiction. Middletown, CT: Wesleyan University Press.

DÍEZ, Julián (2008): "Secesión". Hélice: Reflexiones críticas sobre ficción especulativa, núm. 10, pp. 5-11.

FERRERAS, Daniel F. (1995): Lo fantástico en la literatura y el cine. Madrid: Vosa.

FERRERAS, Juan Ignacio (1972): La novela de ciencia ficción. Madrid: Siglo XXI.

JAMESON, Fredric (2005): Arqueologías del futuro: El deseo llamado utopía y otras aproximaciones de ciencia ficción. Madrid: Akal.

MILNER, Andrew (2004): "Darker Cities: Urban Dystopia and Science Fiction Cinema". International Journal of Cultural Studies, vol. 7, núm. 3, pp. 259-279.

MONTANER, Josep Maria (1991): Fills de Blade Runner. Barcelona: Columna.

- (2001): "Arquitectura y cine: Blade Runner, El show de Truman y otras películas urbanas". Astrágalo: revista cuatrimestral iberoamericana, vol. 17, pp. 115-120.

MORENO, Fernando Ángel (2010): Teoría de la literatura de Ciencia Ficción: Poética y Retórica de lo Prospectivo. Vitoria: Portal Edition.

NEUMANN, D. (ed.) (1996): Film architecture: Set designs from Metropolis to Blade Runner. Munich / London / New York: Prestel.

ROAS, David (2001): "La amenaza de lo fantástico", en David Roas (ed.), Teorías de lo fantástico, pp. 7-44. Madrid: Arco Libros.

- (2011): Tras los límites de lo real: Una definición de lo fantástico. Madrid: Páginas de Espuma.

ROBU, Cornel (ed.) (2006): Teoria pierde omenia / Theory kills sympathy. Cluj-Napoca: Casa Cărţii de Ştiinţă.

SAMBRICIO, Carlos (1996): "De Metrópolis a Blade Runner: dos imágenes urbanas de futuro". Revista de occidente, núm. 185, pp. 45-62.

SUVIN, Darko (1984): Metamorfosis de la ciencia ficción: Sobre la poética e historia de un género literario. México: Fondo de Cultura Económica. 